\title{
The Use of Ketamine in Neuropathic Pain
}

\author{
Sarah Lee O'Brien · Sanjog Pangarkar • \\ Joshua Prager
}

Published online: 9 April 2014

(C) Springer Science + Business Media New York 2014

\begin{abstract}
Hyperactivity of $N$-methyl-D-aspartate (NMDA) receptors may be one of the factors in the genesis of neuropathic pain (NP). Ketamine is a dissociative anesthetic and analgesic that is the most potent NMDA receptor antagonist currently available for human use. There is a growing body of literature for three decades suggesting efficacy of subanaesthetic doses of ketamine in the treatment of NP, particularly the pain in complex regional pain syndromes. The primary limitations of ketamine use are secondary to psychotomimetic and, to a lesser extent, sympathetic activation. The purpose of this article is to review the history, pharmacology, pharmacodynamics, clinical benefits, and limitations of ketamine for treatment of NP. Methods of administration and management of adverse effects are highlighted based on the clinical experience of the authors.
\end{abstract}

Keywords Ketamine $\cdot$ Neuropathic pain $\cdot$ NMDA receptors · Hyperalgesia $\cdot$ Allodynia $\cdot$ Central sensitization $\cdot$ Complex regional pain syndromes

S. L. O'Brien $(\varangle) \cdot$ S. Pangarkar

Pain Medicine Division, Department of Physical Medicine and

Rehabilitation, West Los Angeles Veteran's Administration

Medical Center, UCLA, 11301 Wilshire Boulevard,

Los Angeles, CA 90025, USA

e-mail: sarahleeobrien@ucla.edu

S. Pangarkar

e-mail: sanjog.pangarkar@va.gov

J. Prager

California Pain Medicine Center at UCLA Medical Plaza,

Los Angeles, CA, USA

\section{Introduction}

Neuropathic pain (NP) is defined as a pain state arising from a lesion or disease of the somatosensory system [1]. Conditions associated with NP include infections, trauma, metabolic abnormalities, chemotherapy, surgery, irradiation, neurotoxins, inherited neurodegeneration, nerve compression, inflammation, autoimmune disease, and tumor infiltration [2]. While etiologically heterogeneous, NP syndromes share the primary characteristics of ongoing pain, dysesthesias, and hyperalgesia in the absence of an identifiable stimulus.

There are multiple mechanisms responsible for NP. These maladaptive responses in the nociceptive pathway drive persistently altered processing of both nociceptive and innocuous afferent inputs. Mechanisms underlying NP include altered gene expression, changes in gene regulation within the CNS, changes in ion channels that lead to ectopic activity, and synaptic facilitation of the neural axis producing central amplification [3]. The activation and upregulation of dorsal horn excitatory glutamatergic $N$-methyl-D-aspartate (NMDA) receptors is believed to play a central role in NP, allodynia, and hyperalgesia [4, 5].

First-line treatment options for NP have included tricyclic antidepressants, serotonin/norepinephrine reuptake inhibitors such as duloxetine and venlafaxine, and calcium channel $\alpha_{2} \delta$ agonists such as gabapentin and pregabalin [6]. Yet, NP syndromes have been characteristically resistant to these standard pharmacologic therapies and effective treatments remain a major clinical challenge.

In 1990, the first reports of subanesthetic uses of ketamine were described for cancer pain, with low doses showing efficacy for opioid-resistant pain in cancer patients [7]. Since then, there has been increasing clinical use of low-dose ketamine to provide analgesic effects in a 
wide range of acute and chronic pain conditions [8• $]$. There is a growing body of literature from experimental animal models, human volunteer studies, and small clinical trials that have suggested the efficacy of subanesthetic doses of ketamine in the treatment of various neuropathic conditions $[8 \cdot 9 \cdot 9 \cdot \bullet, 10,11,12 \bullet \bullet, 13]$. However, the psychotomimetic actions of ketamine and its clinical risk-benefit ratio have precluded ketamine's use as a first-line treatment [14]. This selective review of ketamine use in NP is derived from English-language published papers, from 1966 to October 2013, identified through PubMed using the search terms 'ketamine' and 'NP' as well as the clinical experience of the authors. Due to space limitations, it does not provide a comprehensive review, but instead focuses on selected areas of importance. The purpose of this article is to review the history, pharmacology, pharmacodynamics, clinical benefits, and limitations of ketamine for NP.

\section{History of Ketamine}

Ketamine hydrochloride was first synthesized in 1962 by Parke-Davis scientists searching for the ideal anesthetic agent [15]. The scientists were experimenting with chemical derivatives of phencyclidine (PCP) to find a drug with the same anesthetic effect of PCP but with a shorter duration of action and less propensity for hallucinations, prolonged emergence delirium, and other unpleasant psychotic side effects [16]. Clinically approved for human use since 1970 [17], ketamine is well established as a reliable anesthetic agent for induction and maintenance of elective surgery, in emergency out-of hospital medicine, and as an aid in human anesthetic applications, especially trauma, burn, and pediatric patients $[11,18 \bullet \bullet, 19]$. In anesthetic practice, high plasma and brain concentrations of ketamine result in dissociative anesthesia, amnesia, a raised arterial pressure, increased heart rate and cardiac output with relative preservation of airway reflexes and respiration [20].

While the initial interest in ketamine was its use as a sole anesthetic or induction agent, Sadove et al. [21] were the first to explore the analgesic properties of low-dose ketamine in 1971. Their double-blind clinical study in postoperative patients comparing change in pain threshold from low-dose ketamine to that produced by meperidine and placebo suggested the useful clinical application of ketamine in subdissociative low doses as an analgesic [21]. Soon after, the discovery of the NMDA receptor in 1987 [22] and its role in pain processing and spinal neural plasticity triggered renewed interest in ketamine as a potential anti-hyperalgesic agent.

\section{Ketamine's Mechanism of Action}

The mechanism of action of ketamine remained unknown until the early 1980s, when Lodge et al. [23] discovered that low intravenous doses of ketamine and PCP were able to selectively inhibit firing of spinal neurons evoked by NMDA, the prototypical agonist of the glutamate NMDA receptor [23-25]. Ketamine was later established to act as a noncompetitive NMDA antagonist blocking the receptor by binding to its PCP-specific site when the receptor channel is in the open activated state [25-27].

The role of ketamine specifically in NP treatment is based primarily on its potent antagonistic effect of the NMDA receptor, a well-known primary target for the treatment of NP [10]. Activation of NMDA receptors, especially those located within the dorsal horn of the spinal cord, are critically involved in nociceptive transmission, synaptic plasticity inflammation, and nerve injury-induced central sensitization, all of which play a crucial role in the pathogenesis of neuropathic chronic pain [4, 28]. Ketamine inhibits NMDA receptor-mediated responses in the spinal cord [24] and thalamus [29]. Ketamine has also been found to inhibit the 'wind-up' phenomenon, the frequencydependent increase in the excitability of spinal cord neurons evoked by electrical stimulation of C-fiber primary afferent nerves [24, 28]. Ketamine equally binds the NMDA subtypes 2A to 2D; therefore, it is proposed to have a more favorable effect in such heterogenic disease as NP, as compared with NMDA receptor antagonists with more discriminative NMDA subtype selectivity [30].

Besides acting on the NMDA receptor, ketamine's analgesic effect in NP may include interactions with $\mu$ opioid receptors [31], monoamine transporters [32], tolllike receptor 3 (TLR-3) [33], microglial calcium-activated $\mathrm{K}+$ channels [34], and dopamine receptors, as well as other cholinergic, purinergic and adenosine receptor systems [25, 35]. The ability of ketamine to block conductance of specific ion channels may be the reason it has local anesthetic properties after topical administration [36]. Ketamine's high affinity to D2 receptors is also suggested as the cause for typical psychotropic effects observed in humans [37].

Recent studies have also shown ketamine to induce rapid, potent, and prolonged antidepressant effects [38-43]. These growing studies are of particular interest in understanding the efficacy of ketamine in NP treatment given the integral component of mood in the affective component of pain. The biological mechanisms underlying ketamine's antidepressant activity are not fully understood but may involve inhibition of NMDA and upregulation in $\alpha$-amino3-hydroxy-5 methylisoxazole-4-propionic acid (AMPA) receptor expression [44], subsequent activation of the mammalian target of rapamycin (mTOR) intracellular 
cascade [45], and stimulation of neuroplasticity marker brain-derived neurotrophic factor (BDNF) activity [46].

\section{Pharmacology and Pharmocodynamics}

Ketamine is a PCP derivative with a chiral center on the $\mathrm{C}-2$ atom of the ketamine cyclohexane ring. It gives rise to two sterioisomers, $\mathrm{S}(+)$ and $\mathrm{R}(-)$ ketamine. Because of its greater affinity and selectivity for the PCP binding site of the NMDA-receptor, the $\mathrm{S}(+)$ enantiomer parenterally is about 4 times more potent an analgesic than the R-enantiomer $[47,48]$, and twice as potent as the racemic mixture $[14,49]$. In equianalgesic doses, $\mathrm{S}(+)$ ketamine produces fewer psychic disturbances and less agitation than $\mathrm{R}(-)$ ketamine [50].

When used for pain management, ketamine is commonly administered intravenously. However, analgesia has also been delivered via subcutaneous, intramuscular, epidural, intrathecal, intraarticular, oral, topical, intranasal, and sublingual routes [51]. Ketamine rapidly passes the bloodbrain barrier which allows for its rapid analgesic effect with a blood-effect site equilibration half-life of 1-10 min [52]. Ketamine peak plasma concentration is reached within $1 \mathrm{~min}$, has a redistribution half-life of 7-15 min, and clearance of $15 \mathrm{~mL} / \mathrm{kg} / \mathrm{min}$ [53]. Traditionally, IV elimination half-life is reported as 2-3 h [52], although when used in long-term treatment of chronic pain, the analgesic onset/offset half-life of ketamine has been reported as high as 11 days when treated with continuous IV infusion [54].

Oral administration of ketamine undergoes extensive first-pass metabolism in the liver with bioavailability of oral ketamine ranging from 16 to $24 \%$ depending on dosage used [11, 14, 51, 55]. Peak plasma concentrations after oral ingestion are achieved in $\sim 30$ min [14]. Ketamine is primarily metabolized by CYP3A4, CYP2B6, and CYP2C9 to form norketamine, its pharmacologically active metabolite, which is renally excreted [11]. The T1/2 of oral ketamine has been reported to be 5-6 h with elimination half-life of 2-3 $\mathrm{h}$ for ketamine and $\sim 4 \mathrm{~h}$ for norketamine $[11,51]$. Oral ketamine is associated with higher serum levels of norketamine as compared to IV and other routes of administration, and, in chronic use, norketamine is thought to be the primary analgesic agent $[11,14]$.

\section{Evidence for the Use of Ketamine in Neuropathic Pain}

Systematic Reviews on Use of Ketamine in Neuropathic Pain

The first published review on the effectiveness of ketamine in chronic pain management by Hocking and Cousins
[12••] in 2003 found 11 controlled trials, 2 uncontrolled trials, 9 case reports and 2 case series from 1966 to 2002 . The majority of conditions studied were in the NP category including central pain, phantom and ischemic limb pain, post-herpetic neuralgia, orofacial pain, complex regional pain syndrome (CRPS), and fibromyalgia. Based on the reviewed data, the authors report, "ketamine may be used most effectively to reduce the symptoms of allodynia, hyperalgesia, and hyperpathia rather than acting as a traditional analgesic" [12••]. Due to the limited number of randomized controlled trials, heterogeneity of data, and commonly reported psychotomimetic side effects, the review concludes that "the evidence for efficacy of ketamine for treatment of chronic pain is moderate to weak" $[12 \bullet \cdot]$. The authors do support a ketamine trial for patients with severe chronic pain that is incapacitating and refractory to other first- and second-line pharmacological therapies.

Six years later, Bell [56] published a topical review on ketamine use in chronic noncancer pain which included another 18 controlled trials investigating its efficacy in primarily chronic NP. The review concludes while ketamine can provide short-term relief of refractory NP in some patients, data supporting the efficacy and tolerability of ketamine in the long-term treatment of chronic pain is extremely limited [56]. The review cautions that ketamine can be a drug of addiction with neurotoxic effects, unpleasant adverse effects, and long-term safety issues which indicate the need for future carefully controlled clinical trials focusing on optimal dose, route of administration, and duration of treatment.

A year later, in 2009, Blonk and colleagues reviewed the literature on the efficacy of specifically oral ketamine use in chronic pain from 1950 to 2009 [11]. They found that, of the 22 studies acceptable for review, 16 were non-comparative observational studies or anecdotal reports. The review concludes that as there are a very limited number of high quality studies available for review and efficacy and long-term adverse effects are insufficiently studied, oral ketamine may have a limited role as add-on therapy in complex chronic pain patients with severe pain refractory to routine therapeutic options.

In 2012, a Cochrane review [57] assessed the effectiveness and adverse effects of ketamine in the treatment of refractory NP in cancer. The review found 32 case reports or open label uncontrolled studies describing improvement of opioid analgesia with ketamine; however, only 2 RCTs with a total of merely 30 patients met the reviewers' inclusion criteria. With insufficient data to enable any evidence-based conclusions or recommendations about the benefit and harm of adjuvant ketamine, the authors conclude that ketamine may be a treatment option in patients who appear to have a problem tolerating opioids or when 
there are problems with opioid responsiveness. The review highlights the need in future ketamine research for larger, higher quality trials with clearly defined outcomes which are clinically useful, such as relief of NP, reduction of tolerance or reduction of opioid consumption, specific route of administration, which dose is effective, and what are the costs to the patient in terms of adverse events [57].

A summary of the randomized, double-blind controlled studies investigating ketamine use in NP from 1995 to 2013 is included in Table 1.

Literature on Ketamine Use in Central Neuropathic Pain

The efficacy of intravenous, subcutaneous, oral, and transdermal ketamine has been studied in neuropathic central pain primarily in spinal cord injury (SCI) and poststroke patient populations. Fisher and Hagan [58] describe the sustained benefit of oral ketamine $25 \mathrm{mg}$ three times daily in a patient with post-cauda equina NP. To date, there are three randomized, double-blind, placebo-controlled studies which have focused specifically on ketamine's efficacy in chronic NP of spinal origin [59-61]. All three studies demonstrated IV ketamine's efficacy over placebo in decreasing pain pre- and post-treatment, including the intensity of continuous pain [59-61] evoked pain [59], and allodynia [59] in post-traumatic SCI patients. Side effects were minimal in two [62] [61] of the three randomized controlled studies.

Regarding the duration of analgesia from ketamine in spine-mediated NP, Amr [61] studied 40 SCI patients with NP given either placebo, normal saline, or ketamine $80 \mathrm{mg}$ IV. Patients underwent infusion $5 \mathrm{~h}$ daily for 1 week with significant pain improvement found in the ketamine group that lasted up to 2 weeks post-infusion. More recently, Kim et al. [63] found an even greater duration of pain relief in the first study of ketamine's efficacy during the acute phase of NP. Patients were followed for a mean 14.3 months and at the termination of ketamine treatment, VAS pain scores had decreased by $74.6 \%$. At the last clinic visit, $~ 96.8 \%$ of patients experienced complete pain relief. The authors posit that ketamine treatment started before the establishment of central sensitization may be helpful in reducing pain in the chronic phase.

Although there are no published randomized, doubleblind, placebo-controlled studies focused on ketamine use solely in post-stroke patients, Yamomoto et al. [64] found 11 out of 23 patients with central post-stroke pain achieved $>40 \%$ pain reduction temporarily after a total dose $25 \mathrm{mg}$ of IV ketamine was administered over 25 min. Backonja et al. [65] found in 6 patients with both central and peripheral NP, the 2 stroke patients with central NP demonstrated a $>50 \%$ decrease in pain, allodynia and hyperalgesia for $2-3 \mathrm{~h}$ after single injection of ketamine $250 \mathrm{mcg} / \mathrm{kg}$ delivered over $5 \mathrm{~min}$.

Administration of $\mathrm{S}(+)$ ketamine has twice the analgesic potency of racemic $\mathrm{R}(-)$ ketamine and in equianalgesic doses produces fewer psychic disturbances and less agiation than $\mathrm{R}(-)$ ketamine [50]. The efficacy of $\mathrm{S}(+)$ ketamine via iontophoresis-assisted transdermal delivery at 50 and $75 \mathrm{mg}$ doses was studied in 33 patients with central NP secondary to stroke, spinal cord lesion, thalamus lesion, brainstem infarct, multiple sclerosis, and Parkinson's disease [50]. Although there was no improvement in pain after 1 week with either 50 or $75 \mathrm{mg} \mathrm{S}(+)$ ketamine doses, there were significant improvements in scores evaluating health status and quality of life after 1 week of $75 \mathrm{mg} \mathrm{S}(+)$ ketamine administration via without adverse effects.

\section{Literature on Ketamine Use in Peripheral Neuropathic Pain}

The efficacy of intravenous, subcutaneous, oral, topical, and intranasal ketamine has been studied in peripheral NP. There are at least 9 randomized, double-blind trials demonstrating the efficacy of ketamine in NP [66-75]. In patients with post-nerve injury NP, ketamine administered IV has shown significant reduction in pain and allodynia as compared to placebo [66-70, 73, 74] as well as compared to morphine [73]. Niesters et al. [73] report the duration of analgesia after IV ketamine infusion in peripheral NP was reported as $>6 \mathrm{~h}$ in 2 out of 10 patients and $>12 \mathrm{~h}$ in 8 out of 10 patients.

Intranasal use of the more potent enatiomer (S) ketamine at doses of 0.2 and $0.4 \mathrm{mg} / \mathrm{kg}$ was studied in 16 patients with NP and showed a significant reduction in NP that was dose-dependent, lasting 2-3 $\mathrm{h}$ with maximum pain reduction of 30-40\% at $50 \mathrm{~min}$ after application [72]. The two randomized, double-blind, placebo-controlled studies on topical administration of ketamine did not show efficacy in the treatment of peripheral NP with no effect from ketamine $1 \%$ topical cream applied three times daily for 3 weeks in 92 patients with peripheral NP [76] or when ketamine $5 \%$ topical cream was applied for 1 month in 17 patients with diabetic peripheral neuropathy [75].

\section{Literature on Ketamine Use in Postherpetic Neuralgia}

The use of IV ketamine as a single bolus of $0.15 \mathrm{mg} / \mathrm{kg}$ over 10 min showed significant reduction in pain including windup-like pain as compared to both placebo and morphine in 8 patients with postherpetic neuralgia (PHN) [62]. However, the topical administration of S-Ketamine $1 \%$ applied either four times daily for 15 days [77] or R-ketamine $1 \%$ applied three times daily for 3 weeks [76] did not demonstrate any benefit over placebo in patients with PHN. 


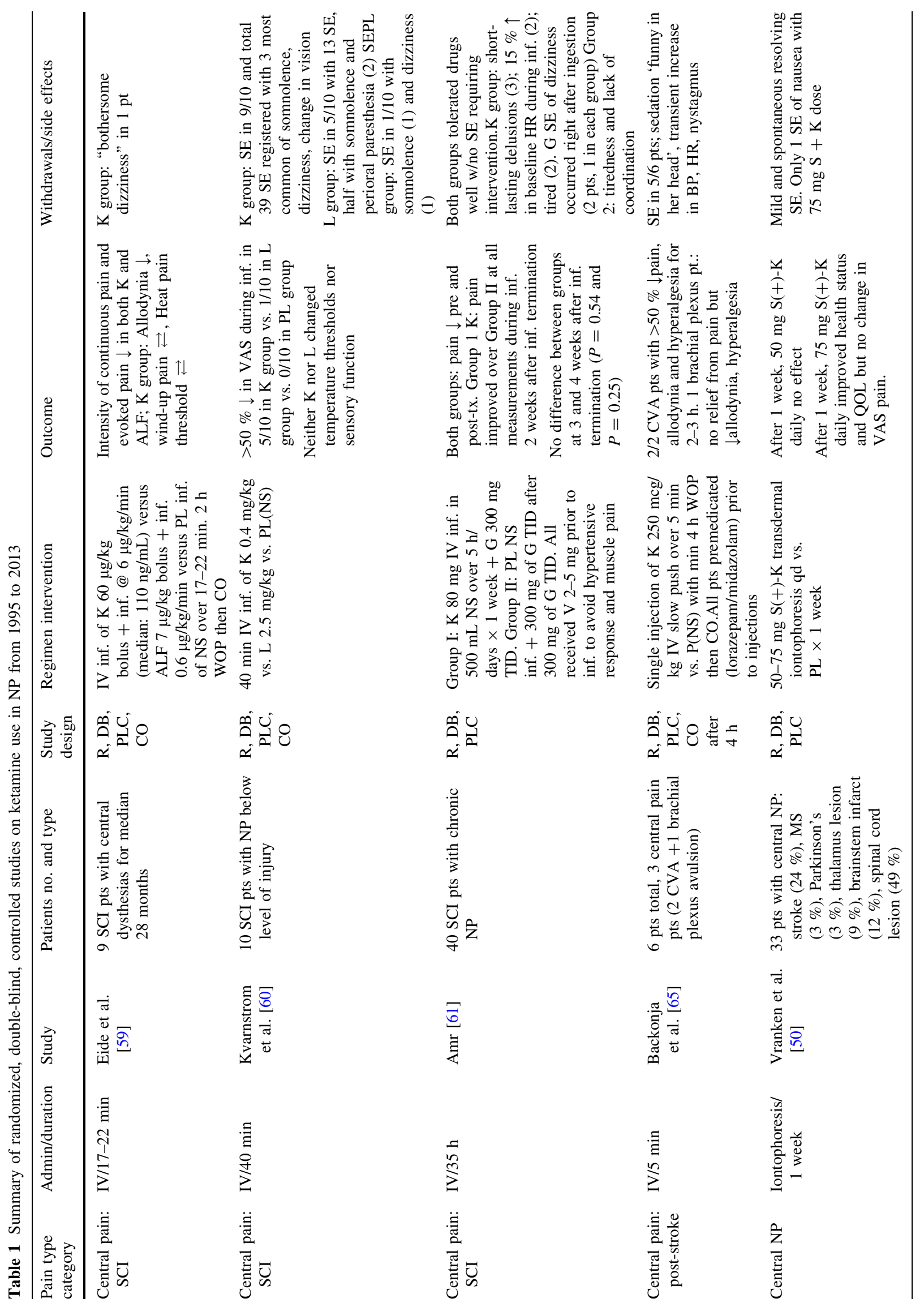




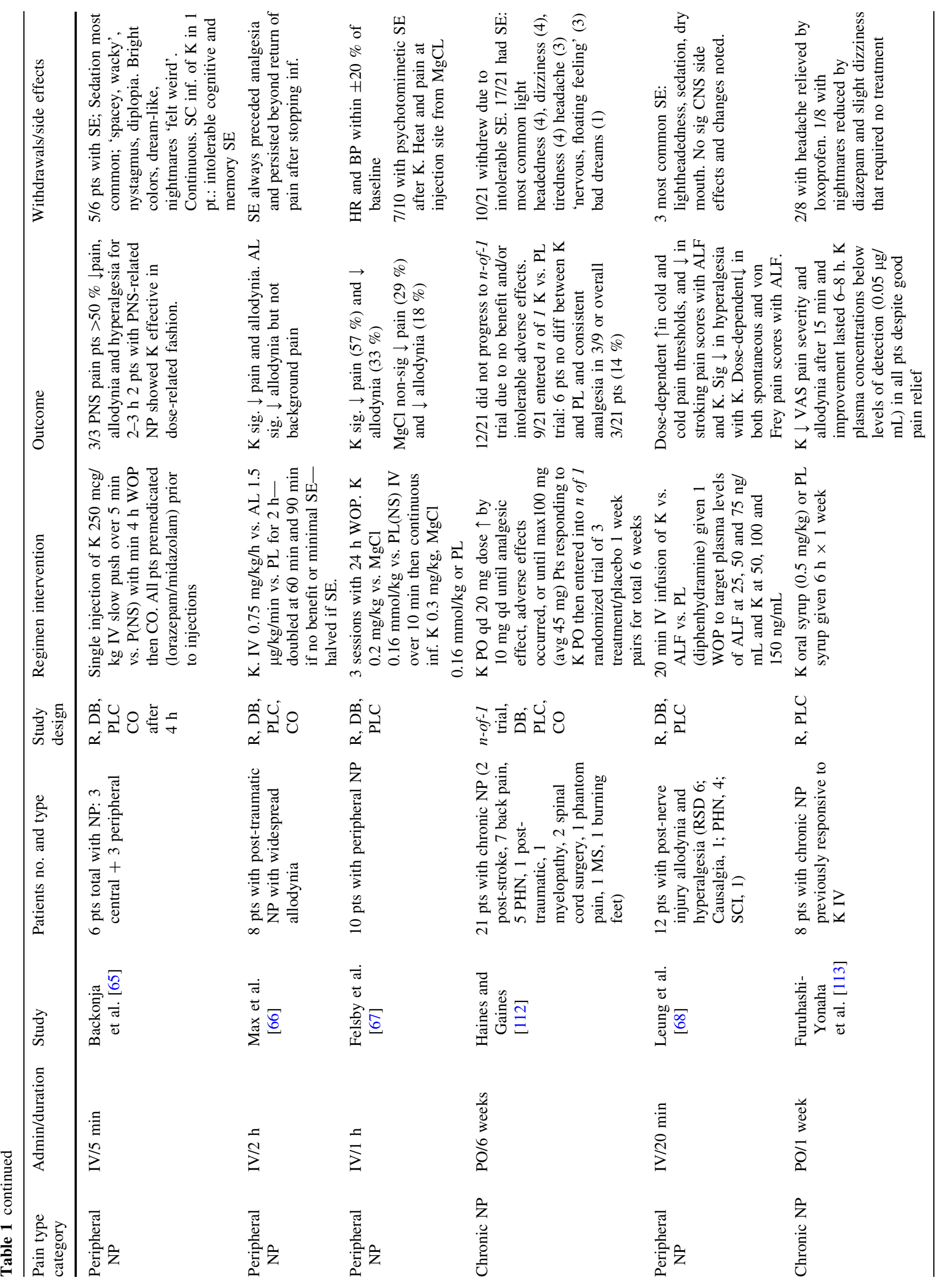




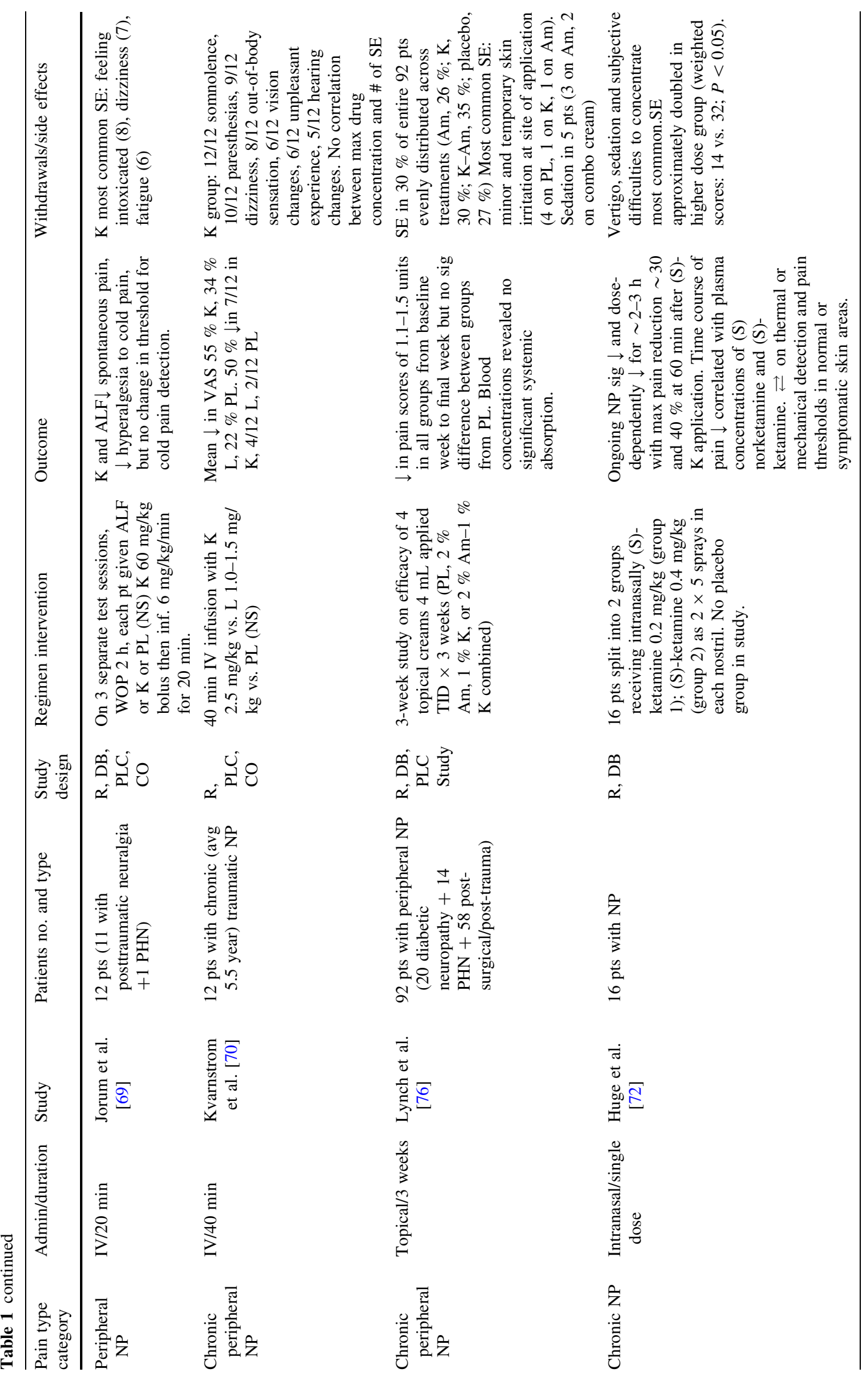




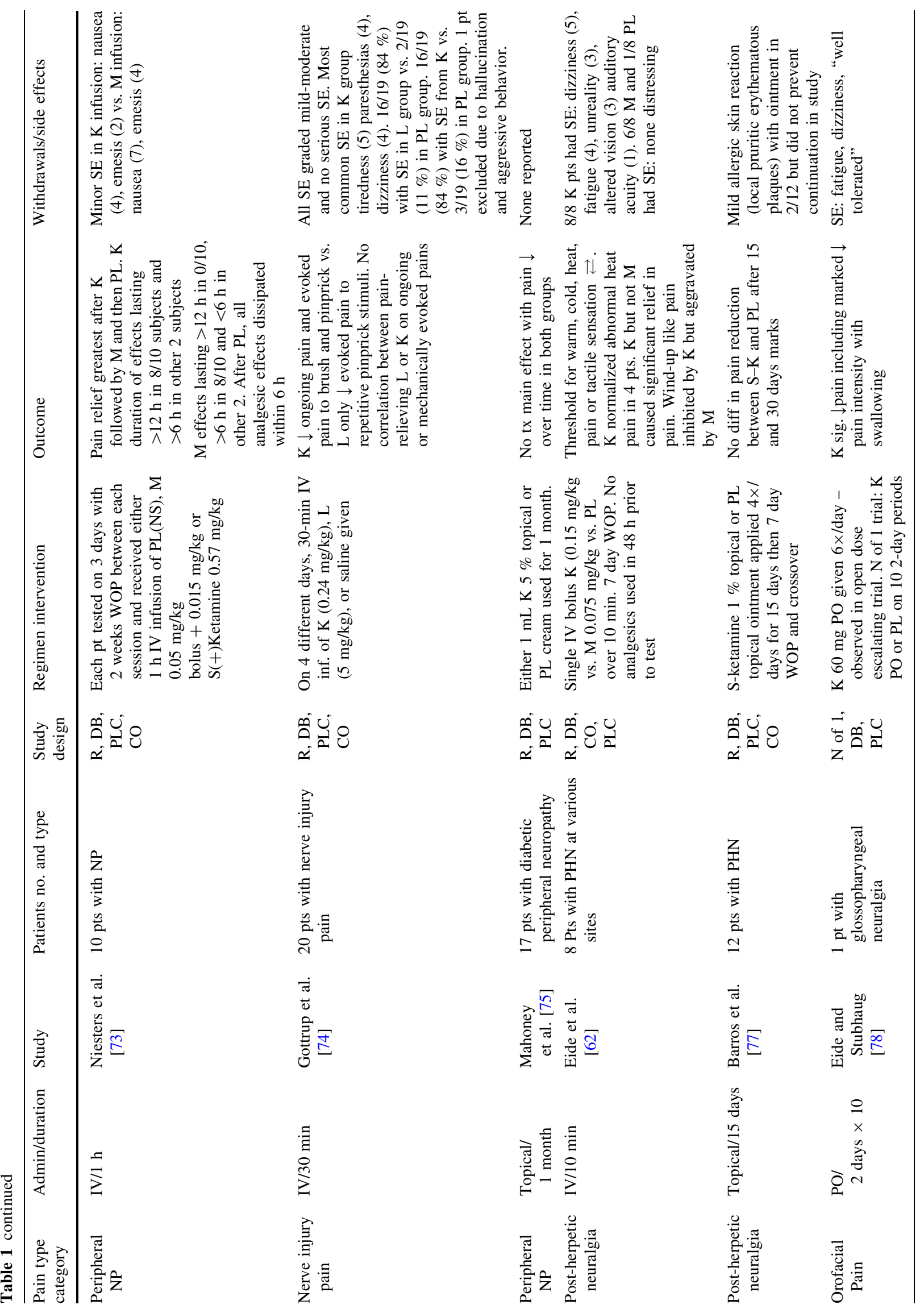




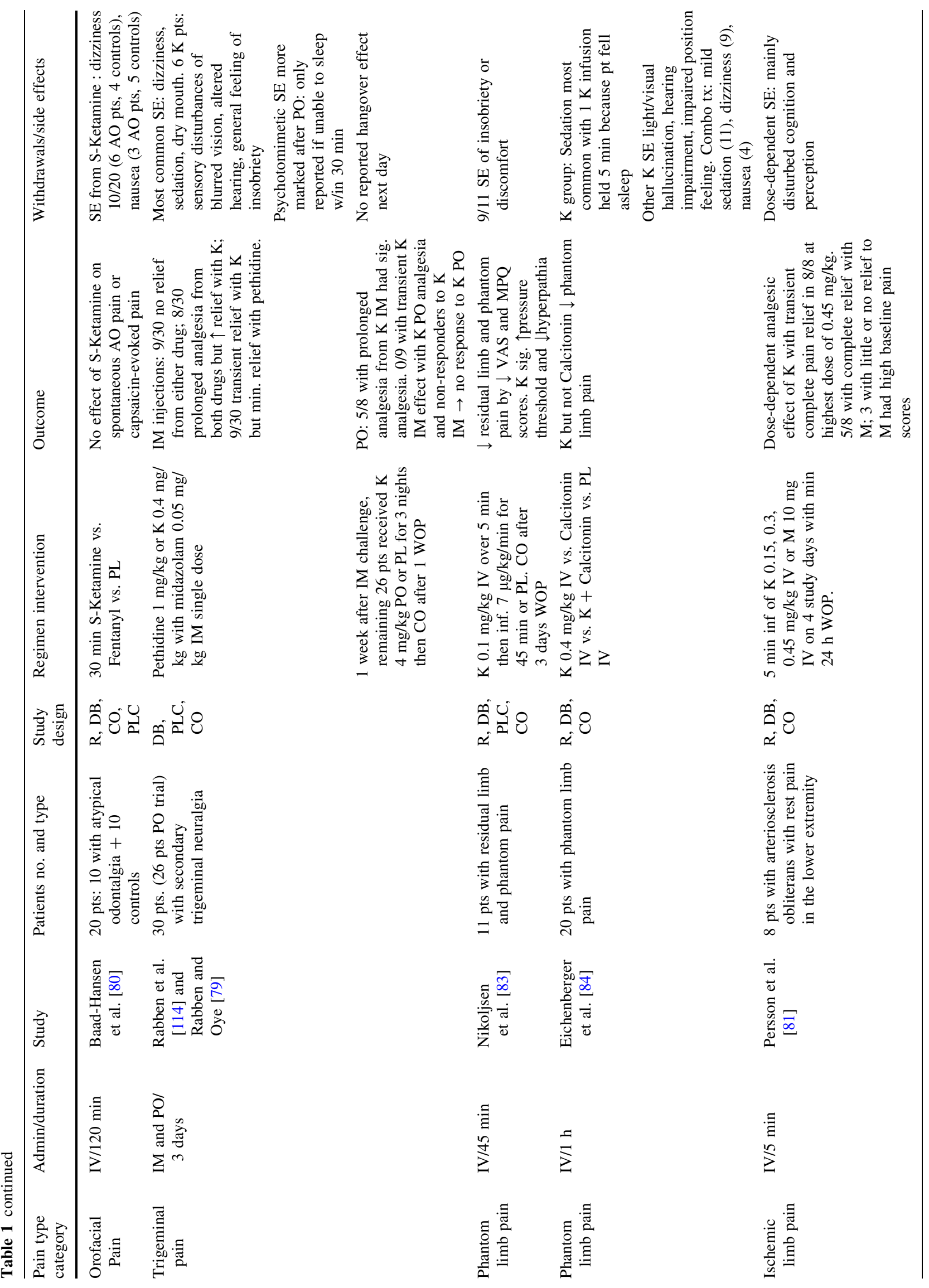




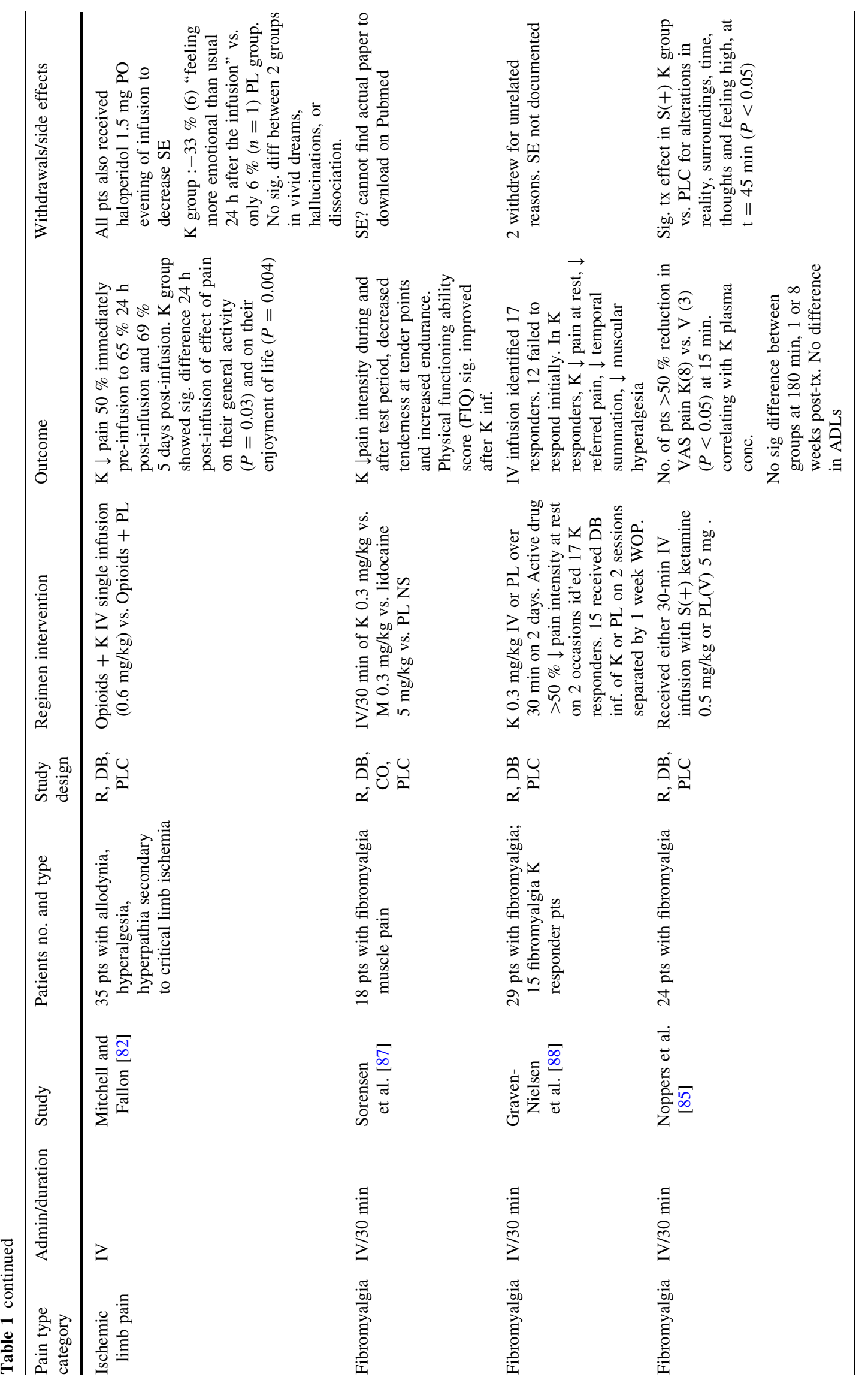




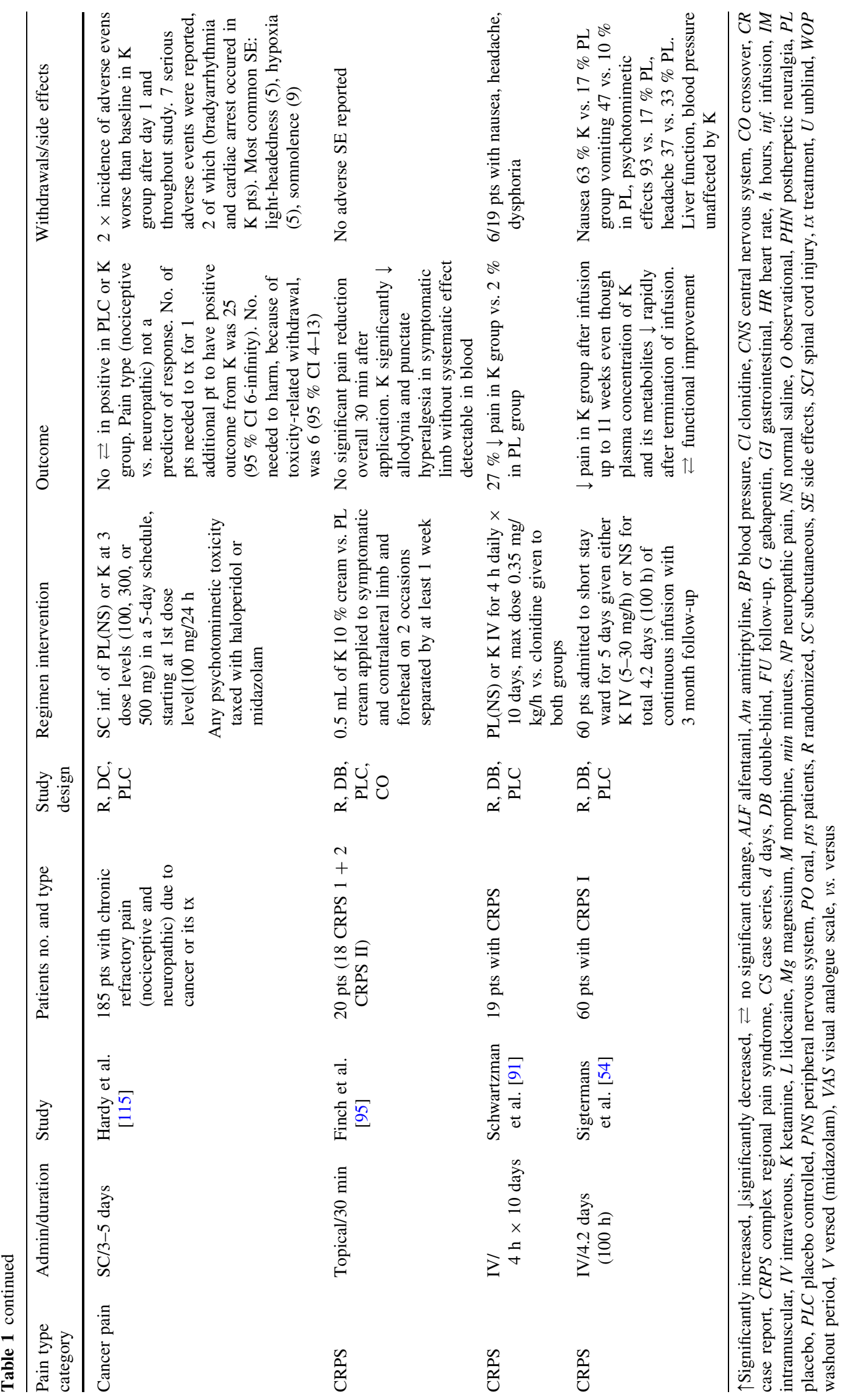




\section{Literature on Ketamine Use in Orofacial Pain}

Eide and Stubhaug [78]. reported significant pain reduction with swallowing as compared to placebo in a $n$ of 1 study in which oral ketamine $60 \mathrm{mg}$ was given six times daily in a patient with glossopharyngeal neuralgia. Rabben and Oye [79] evaluated both intramuscular and oral efficacy of ketamine in 30 patients with secondary trigeminal neuralgia in a double-blind, placebo-controlled crossover study and found of the 26 patients who proceeded to the oral trial of ketamine $4 \mathrm{mg} / \mathrm{kg}$ for 3 nights, 5 of the 8 patients with prolonged analgesia from IM ketamine demonstrated significant pain relief as compared to placebo. However, there was no significant benefit on spontaneous or capsaicinevoked pain in a study of 10 patients with atypical odontalgia when S-ketamine was given IV over 120 min [80].

Literature on Ketamine Use in Ischemic Limb Pain and Phantom Limb Pain

Ketamine administered IV has shown efficacy in 2 randomized, double-blind studies in patients with ischemic limb pain [81, 82]. Persson et al. [81] found a dose-dependent analgesic effect with ketamine infusions at $0.15,0.3$, and $0.45 \mathrm{mg} / \mathrm{kg}$ IV with transient complete pain relief in all 8 patients at the highest dose of $0.45 \mathrm{mg} / \mathrm{kg}$. Side effects were reported as dose-dependent and mainly experienced as disturbed cognition and perception. Mitchell and Fallon [82] also found that a single ketamine infusion-administered $0.5 \mathrm{mg} / \mathrm{kg}$ IV provided reduction in pain at $24 \mathrm{~h}$ and 5 days post-infusion over placebo in 35 patients with allodynia, hyperalgesia, and hyperpathia secondary to critical limb ischemia. There was also significant improvement $24 \mathrm{~h}$ post-infusion of the effect of pain on their general activity and enjoyment of life over the placebo group. Ketamine administered intravenously in doses ranging from $7 \mathrm{mcg} / \mathrm{kg} / \mathrm{min}$ to $0.4 \mathrm{mg} / \mathrm{kg}$ for $45-60 \mathrm{~min}$ also showed efficacy in decreasing residual limb and phantom pain in two randomized, double-blind crossover studies [83, 84].

\section{Literature on Ketamine Use in Fibromyalgia}

Although there is ongoing debate whether fibromyalgia is neuropathic in origin [85], fibromyalgia pain has been associated with central sensitization and malfunctioning sensory processing within the central nervous system [86]. Three randomized, double-blind studies have been published on the use of ketamine in fibromyalgia pain [85, 87, 88]. Sorensen et al. [87] found that ketamine IV $0.3 \mathrm{mg} / \mathrm{kg}$ administered over 30 min resulted in a significant decrease in pain intensity during and after the test period, decreased tenderness at tender points, and increased endurance in 18 patients with fibromyalgia. Most notably, physical functioning ability scores improved significantly in the fibromyalgia patients after ketamine infusion. GravenNielsen et al. [88] studied the use of ketamine $0.3 \mathrm{mg} / \mathrm{kg}$ IV over 30 min versus placebo in 29 patients with fibromyalgia and found that of the 17 of 29 identified as ketamine responders, those patients experienced significant decrease in pain at rest, referred pain, temporal summation, and muscular hyperalgesia. Noppers et al. [85] studied the use of $\mathrm{S}(+)$ ketamine $0.5 \mathrm{mg} / \mathrm{kg}$ IV over $30 \mathrm{~min}$ and found $>50 \%$ reduction in pain relief in the ketamine group versus placebo group at $15 \mathrm{~min}$ but no improvements were found in activities of daily living scores at $180 \mathrm{~min}, 1$ or 8 weeks post-treatment.

\section{Literature on Ketamine Use in Complex Regional Pain Syndrome}

The basic features of CRPS include pain disproportionate to the injury, allodynia and hyperalgesia, and autonomic abnormalities [9*0]. One of the hallmarks of CRPS is that of central sensitization caused by a reduction in the firing threshold of $\mathrm{A} \delta$ and $\mathrm{C}$ fibers leading to the ongoing release of neurotransmitters and peptide neuromodulators from peripheral afferent terminals [89]. As the most potent clinically available NMDA receptor antagonist, ketamine is an ideal candidate in the treatment of CRPS because of its potential to reverse central sensitization, alter neural plasticity and reduce neuroinflammation [90].

A comprehensive systematic review of literature up to May 2011 evaluating the efficacy of ketamine in CRPS treatment by Azari et al. [9••] found three randomized, placebo-controlled trials, seven observational studies, and nine case reports/series. The authors conclude, "ketamine has both acute efficacy and long-term implications in the management of complex regional pain." A recent 5-year retrospective analysis by Patil and Anitescu [13] investigating the efficacy of outpatient ketamine infusions in patients with severe refractory pain of multiple etiologies also demonstrated significant reduction in VAS pain scores in patients with CRPS.

The Scwartzman et al. [91] randomized, placebo-controlled trial studied the efficacy of ketamine IV infusions at $25 \mathrm{~mL} / \mathrm{h}$ for $4 \mathrm{~h}$ daily for 10 days versus placebo infusions in 19 CPRS patients. At 12 weeks post-treatment, significant decreases in pain in most affected area, burning pain, pain when touched or lightly touched or brushed lightly, overall pain level, as well as decreased nighttime awakening were found in the ketamine group. Although the study showed that ketamine infusions significantly reduced the affective component of pain by $50 \%$ for 3 months, no changes in quality of life measures were found.

The Sigtermans et al. [54] randomized, double-blind, placebo-controlled, parallel-group trial in 60 CRPS patients found that after a 4.2 days/100 h continuous IV ketamine 
infusion, pain scores were lower in the ketamine group over a 12-week period with the lowest pain scores seen 1 week after ketamine treatment completion. No functional improvement in the ketamine group was initially found despite pain relief; however, a follow-up secondary analysis [92] of time-dependent data between pain and motor function found pain intensity was significantly inversely related to motor function, irrespective of whether patients had received ketamine or placebo. The authors suggest that, because patients were unaware of possible effects of ketamine on motor function, motor function changes could be mediated by, or occur simultaneously with, changes in pain intensity [92].

Dahan et al. [93] also performed a randomized, placebocontrolled trial of 60 CRPS- 1 patients allocated to receive either 100-h IV infusion of $S(+)$ ketamine or placebo with drug infusion rate increased from $5 \mathrm{mg} / \mathrm{h} / 70 \mathrm{~kg}$ to $20 \mathrm{mg} / \mathrm{h}$ based on the effect/side effect profile. The study also demonstrated IV ketamine's prolonged duration of pain relief with significant pain relief in the ketamine group with analgesia outlasting the treatment period by 50 days [93].

Correll et al. [94] demonstrated the potential benefit of follow-up repeat ketamine infusions in their retrospective study in which 12 of 33 CPRS patients who received a second treatment of intravenous ketamine infusion (doses from 10 to $50 \mathrm{mg} / \mathrm{h}$ for a mean of 4.7 days) achieved a longer duration of pain relief after the first treatment [94]: $54 \%$ of 33 patients were pain-free at 3 months and $31 \%$ remained pain-free at 6 months after a single ketamine infusion. Following a repeat ketamine infusion, $58 \%$ of 12 patients had pain relief at 1 year and $\sim 33 \%$ remained pain- free for more than 3 years.

While the majority of ketamine use in CRPS research has studied intravenous administration, Finch et al. [95] studied the use of topical $10 \%$ ketamine in patients with CRPS in a randomized, crossover, placebo-controlled study of 20 CPRS patients. There was no significant pain reduction in the topical ketamine group. However, a significant reduction in allodynia and hyperalgesia to punctate stimuli in the affected extremity was demonstrated, which the authors report is likely due to ketamine's effect at cutaneous NMDA receptors given systemic ketamine levels were not detectable.

\section{Discussion}

\section{Route of Administration}

Of the various routes of administration including subcutaneous, intravenous, intranasal, oral, and topical applications, studies with ketamine administered intravenously have provided the greatest treatment efficacy in NP.
Topical administration of ketamine at any concentration has not shown any significant benefit in the reduction of neuropathic resting pain in lower concentrations of $1-5 \%$, although at concentrations of $10 \%$, it has demonstrated efficacy in the treatment of allodynia. Although the literature has demonstrated some efficacy for oral and intranasal applications in the treatment of NP, therapeutic use is highly limited by difficulties in controlling and monitoring its administration and possible adverse effects. It is our opinion that the potential risks of diversion, abuse as a recreational drug [89] as well as its reported potential to facilitate date-rape [96, 97], unfortunately far outweigh oral ketamine's potential therapeutic benefit in clinical practice.

\section{Optimal Dose and Duration}

There is no consensus in the literature regarding the optimal dose or duration of treatment of ketamine in NP. Ketamine doses have varied greatly among different studies with effective oral doses ranging from 45 to $1,000 \mathrm{mg}$, and duration of oral ketamine treatment has ranged from several months up to a maximum of more than 1 year [11]. Intravenous infusion dosages in the literature have ranged from 0.35 to a high of $7 \mathrm{mg} / \mathrm{kg} / \mathrm{h}[98,99]$. The titration of ketamine infusions has also differed with some studies titrating in set intervals while others titrating to analgesia or feelings of inebriation [54]. Reported durations of intravenous ketamine infusions have also varied from minutes to hours to infusions up to 10 days $[11,91]$.

\section{Adverse Effects and Complications of Therapy}

Given that NMDA receptor-mediated transmission is involved in the processing of sensory information in the brain [48], it is expected that administration of antagonists at this receptor will lead to a number of side effects. Confusion, delirium, vivid dreams, hallucinations, and feelings of detachment from the body are associated with ketamine use and are particularly prominent on emergence from ketamine [19]. The most common major side effects in outpatient ketamine infusion protocols utilizing midazolam and clonidine report nausea, headache, tiredness, or dysphoria [54]. In studies such as Sigtermans et al. [54] which used infusion protocols without clonidine or midazolam premedication, there was a $93 \%$ incidence of psychotomimetic effects with nausea noted in $63 \%$, vomiting in $47 \%$, and headache in $37 \%$.

Similar to PCP, ketamine has also been a drug of abuse, taken recreationally for its hallucinogenic and euphoric action [89]. Although ketamine has been safely used for over 35 years in clinical anesthesia, concerns have been raised regarding NMDA antagonist-induced neurotoxicity 
[100]. Olney et al. [101, 102] have described these neurotoxic effects of ketamine and other NMDA antagonists in neurodegenerative changes seen in corticolimbic regions of adult rat brains; however, these neurotoxic effects have not been reported in humans [100]. Subanesthetic doses of ketamine have been associated with impaired attention, memory, and judgment, and ketamine has even been used as a pharmacological model for acute schizophrenia [14].

Although cardiac and neurologic toxicities have also been reported from the use of ketamine including tachycardia and intracranial hypertension [14], ketamine's deleterious effect on liver and urinary tract function has been noted most frequently. Kiefer et al. [98] reported evidence of liver dysfunction in 16 out of 20 patients receiving ketamine infusions with transient elevations in liver enzymes, creatine kinase, and CK-myocardiac band during treatment. All levels returned to reference ranges at 10-14 days after the infusion. Noppers et al. [103] also report 3 cases of drug-induced liver injury following repeated courses of $S(+)$ ketamine treatment for CRPS 1 in 6 patients with elevated liver enzymes, all $\geq 3$ times the upper limit of normal and modestly increased eosinophilic leukocytes. All 3 affected patients received 2 ketamine exposures within 4 weeks' time, while 3 patients receiving ketamine at a wider time interval of 12 weeks had no signs of liver injury. The authors suggest there may be an increased risk for ketamine-induced liver injury when infusions are prolonged or repeated within a short time frame.

The use of ketamine can cause urinary tract symptoms, including frequency, urgency, urge incontinence, dysuria, and hematuria $[104,105]$. Urinary dysfunction was found in more than $25 \%$ of recreational users of ketamine, with a dose and frequency response relationship established [106]. Although the causal agent has not been determined, direct irritation by ketamine and its metabolites is a possibility [14]. Investigations have revealed interstitial cystitis, detrusor overactivity, decreased bladder capacity, vesicoureteric reflux, hydronephrosis, papillary necrosis, and renal impairment [52, 104-108].

\section{Clinical Experience}

We believe in the significant benefits of ketamine intravenous infusions in the treatment and management of a specific subgroup patients with CRPS. We have had very limited success with non CRPS neuropathic pain. Collectively, we have performed over 700 ketamine infusions since 2006 in our clinical practice. It is our personal clinical experience that ketamine infusions have the greatest success in the treatment of NP with a sympathetic component responsive to pure sympathetic blockade. Of note, in patients with NP and concomitant clinical depression, we have observed a marked improvement in depression after ketamine infusions, which is in concordance with the robust expanding evidence of ketamine's rapid and potent antidepressant effects [38-43]. The effect on clinical depression has been noted before the effect on the pain. We find that ketamine infusions in NP treatment are particularly effective given the clustering of chronic pain with depression occurs at such a high prevalence, ranging from 30 to $60 \%$ [109-111].

The key to achieving success with ketamine involves safeguarding from adverse events by premedicating patients appropriately, individualizing therapy, and strict monitoring of vital signs. Cardiorespiratory monitoring is an essential component of risk management. No single protocol has predicted success as some patients have found benefit with two or three infusions, whereas others have required 10 days of treatment. In our practice, we find it important to try to wean off opiates as much as possible prior to ketamine infusion because of the higher risk of opioids in combination with midazolam of developing respiratory depression. All patients must receive medical clearance prior to prolonged ketamine infusion treatments. Prior to administering ketamine IV infusion, we recommend premedicating patients with clonidine, ondansetron, and midazolam. We use clonidine for its neuroprotective effects from NMDA antagonists [102], and have also seen its benefit in controlling increased blood pressures and assistance in minimizing dissociative effects. We premedicate with ondansetron to help prevent the otherwise common adverse effect of nausea and emesis with high doses of ketamine. We use midazolam and titrate effect to achieve amnesia to keep patients peaceful before starting the ketamine infusions. In rare cases when patients are refractory to midazolam, we may use pre-infusion doses of oral diazepam. Occasional use of intramuscular anti-psychotic medication is necessary when patients are refractory to benzodiazepines.

In our clinical experience, for logistical issues, we perform a trial of 3 infusions in an outpatient surgical center prior to administering any prolonged daily treatment of ketamine infusions to assess for responsiveness, efficacy, and tolerability of side effects. In ketamine naïve patients, we administer between 100 and $200 \mathrm{mg}$ during a 4-h intravenous infusion starting at low doses. We then schedule patients to receive ketamine infusions in the outpatient surgery center with IV infusions for up to $4 \mathrm{~h}$ daily for up to 10 days with duration dependent on response to treatment. Patients' vital signs are monitored continuously throughout the infusions. If the patient has tolerated previous treatments successfully, then consideration is given for increasing the infusion rate, though this may increase the number of side effects. Labetalol and intravenous fluids are rarely administered to maintain blood pressure at appropriate levels. The 
highest dosing that has been used clinically has been titrated to by the authors is $1,800 \mathrm{mg} /$ day in one patient who was tolerant to ketamine effect and side effects.

Of the adverse effects most commonly encountered, we have seen nausea and very rarely vomiting and have treated this effectively with ondansetron or, if severe, with granisetron intravenously and subsequently orally. Meclizine is beneficial post-infusion to assist with nystagmus and related nausea. We have seen a small percentage of patients who are prone to tension headaches prior to ketamine use re-experience headache during ketamine infusions that are responsive to ketorolac. All our patients are also treated with clonazepam $0.5 \mathrm{mg} 1-2$ tab orally nightly starting the first night of infusion to reduce the incidence of emergent phenomena. Only if necessary, olanzapine $25 \mathrm{mg}$ qhs or other antipsychotics have been used if these symptoms are not responsive to benzodiazepines.

We have seen the majority of our patients benefit with $>50 \%$ pain relief after 10-day infusions treatment which lasts on average up to 3 months (some requiring no subsequent infusions) before patients may return for "booster infusions" which are typically 3 infusions. We have observed rapid resolution of flagrant edema post-infusion. In patients with movement disorders, we usually observe marked resolution of these symptoms prior to achieving pain relief. We have also seen more benefit when patients with CRPS who are treated earlier and typically require lower doses to titrate to effect.

\section{Conclusions}

Based on the review of current literature, we have found efficacy for ketamine infusions in a variety of NP etiologies. In our experience in treating NP with ketamine, we note a safe margin of tolerability evidenced by the low degree of severity for the documented side effects. A thorough review of our recording and management of side effects is in process. Identifying the patients who may benefit as ketamine responders is ongoing with clinical trials and research that suggest there are certain individuals and etiology subtypes whose NP may or may not respond to ketamine [5]. We find that CRPS patients with refractory pain have demonstrated the greatest benefit from ketamine via IV infusions. The literature suggests that prolonged or repetitive infusions may be required to ensure prolonged pain relief in chronic NP. We recognize that there are several limitations for ketamine intravenous use in NP. The recent reports of urologic and hepatotoxic effects from therapeutic use of ketamine dictate an extremely cautious and prudent approach to its use in the clinical practice of NP management. Yet, the studies on the efficacy of ketamine in treatment of refractory NP demonstrate there is clearly a definite population of patients with NP, for whom the benefits of ketamine intravenous infusion treatment considerably outweigh the risks and other available alternatives.

Acknowledgments The authors would like to thank Dr. D. Fish of the University of California-Los Angeles for his review of the manuscript.

\section{Compliance with Ethics Guidelines}

Conflict of Interest S. L. O'Brien declares no conflicts of interest. S. Pangarkar declares no conflicts of interest. J. Prager declares no conflicts of interest.

Human and Animal Rights and Informed Consent This article does not contain any studies with human or animal subjects performed by any of the authors.

\section{References}

Papers of particular interest, published recently, have been highlighted as:

- Of importance

-• Of major importance

1. Jensen TS, et al. A new definition of neuropathic pain. Pain. 2011;152(10):2204-5.

2. Dworkin RH, et al. Advances in neuropathic pain: diagnosis, mechanisms, and treatment recommendations. Arch Neurol. 2003;60(11):1524-34.

3. Costigan M, Scholz J, Woolf CJ. Neuropathic pain: a maladaptive response of the nervous system to damage. Annu Rev Neurosci. 2009;32:1-32.

4. Woolf CJ, Thompson SW. The induction and maintenance of central sensitization is dependent on $N$-methyl-D-aspartic acid receptor activation; implications for the treatment of post-injury pain hypersensitivity states. Pain. 1991;44(3):293-9.

5. Swartjes M, et al. Ketamine does not produce relief of neuropathic pain in mice lacking the beta-common receptor (CD131). PLoS ONE. 2013;8(8):e71326.

6. Fallon MT. Neuropathic pain in cancer. Br J Anaesth. 2013; 111(1):105-11.

7. Oshima E, et al. Continuous subcutaneous injection of ketamine for cancer pain. Can J Anaesth. 1990;37(3):385-6.

8. Persson J. Ketamine in pain management. CNS Neurosci Ther. 2013;19(6):396-402. Fascinating narrative on the history and evolution of ketamine use in pain management.

9. $\bullet$ Azari P, et al. Efficacy and safety of ketamine in patients with complex regional pain syndrome: a systematic review. CNS Drugs. 2012;26(3):215-28. Provides comprehensive review of the efficacy and safety of ketamine specifically in the treatment of CRPS.

10. Fisher K, Coderre TJ, Hagen NA. Targeting the $N$-methyl-Daspartate receptor for chronic pain management. Preclinical animal studies, recent clinical experience and future research directions. J Pain Symptom Manag. 2000;20(5):358-73.

11. Blonk MI, et al. Use of oral ketamine in chronic pain management: a review. Eur J Pain. 2010;14(5):466-72.

12. $\bullet$ Hocking G, Cousins MJ. Ketamine in chronic pain management: an evidence-based review. Anesth Analg. 2003;97(6):1730-9. 
Provides the first systematic literature review of the use of all forms of ketamine in various chronic pain etiologies including studies up to August 2002.

13. Patil S, Anitescu M. Efficacy of outpatient ketamine infusions in refractory chronic pain syndromes: a 5-year retrospective analysis. Pain Med. 2012;13(2):263-9.

14. Quibell R, et al. Ketamine*. J Pain Symptom Manag. 2011; 41(3):640-9.

15. Corssen G, Domino EF. Dissociative anesthesia: further pharmacologic studies and first clinical experience with the phencyclidine derivative CI-581. Anesth Analg. 1966;45(1):29-40.

16. Sinner B, Graf BM. Ketamine. Handb Exp Pharmacol. 2008; 182:313-33.

17. Reich DL, Silvay G. Ketamine: an update on the first 25 years of clinical experience. Can J Anaesth. 1989;36(2):186-97.

18. $\bullet$ Visser E, Schug SA. The role of ketamine in pain management. Biomed Pharmacother. 2006;60(7):341-8. Provides excellent review and analysis of use of low-dose ketamine. Identifies ketamine's primary role in the treatment of opioid resistant or central sensitisation pain with hyperalgesia or allodynia.

19. Domino EF. Taming the ketamine tiger. 1965. Anesthesiology. 2010;113(3):678-84.

20. Slikker W Jr, et al. Ketamine-induced neuronal cell death in the perinatal rhesus monkey. Toxicol Sci. 2007;98(1):145-58.

21. Sadove MS, et al. Analgesic effects of ketamine administered in subdissociative doses. Anesth Analg. 1971;50(3):452-7.

22. Foster AC, Fagg GE. Neurobiology. Taking apart NMDA receptors. Nature. 1987;329(6138):395-6.

23. Lodge D, Anis NA, Burton NR. Effects of optical isomers of ketamine on excitation of cat and rat spinal neurones by amino acids and acetylcholine. Neurosci Lett. 1982;29(3):281-6.

24. Davies SN, Lodge D. Evidence for involvement of $N$-methylaspartate receptors in 'wind-up' of class 2 neurones in the dorsal horn of the rat. Brain Res. 1987;424(2):402-6.

25. Chizh BA. Low dose ketamine: a therapeutic and research tool to explore $N$-methyl-D-aspartate (NMDA) receptor-mediated plasticity in pain pathways. J Psychopharmacol. 2007;21(3):259-71.

26. Zukin SR, et al. Specific binding of $[3 \mathrm{H}]$ phencyclidine in rat central nervous tissue: further characterization and technical considerations. Brain Res. 1983;258(2):277-84.

27. Lodge D, Johnson KM. Noncompetitive excitatory amino acid receptor antagonists. Trends Pharmacol Sci. 1990;11(2):81-6.

28. Zhou HY, Chen SR, Pan HL. Targeting $N$-methyl-D-aspartate receptors for treatment of neuropathic pain. Expert Rev Clin Pharmacol. 2011;4(3):379-88.

29. Salt TE, Wilson DG, Prasad SK. Antagonism of $N$-methylaspartate and synaptic responses of neurones in the rat ventrobasal thalamus by ketamine and MK-801. $\mathrm{Br} \mathrm{J}$ Pharmacol. 1988;94(2):443-8.

30. Collins S, et al. NMDA receptor antagonists for the treatment of neuropathic pain. Pain Med. 2010;11(11):1726-42.

31. Eide PK, et al. Reply to ST Meller: Ketamine: relief from chronic pain through actions at the NMDA receptor. Pain. 1997;72(1-2):289-91.

32. Lindefors N, Barati S, O'Connor WT. Differential effects of single and repeated ketamine administration on dopamine, serotonin and GABA transmission in rat medial prefrontal cortex. Brain Res. 1997;759(2):205-12.

33. Mei XP, et al. Ketamine depresses toll-like receptor 3 signaling in spinal microglia in a rat model of neuropathic pain. Neurosignals. 2011;19(1):44-53.

34. Hayashi $\mathrm{Y}$, et al. Microglial $\mathrm{Ca}(2+)$-activated $\mathrm{K}(+)$ channels are possible molecular targets for the analgesic effects of S-ketamine on neuropathic pain. J Neurosci. 2011;31(48): 17370-82.
35. Persson J. Wherefore ketamine? Curr Opin Anaesthesiol. 2010;23(4):455-60.

36. Ushida $\mathrm{T}$, et al. Analgesic effects of ketamine ointment in patients with complex regional pain syndrome type 1. Reg Anesth Pain Med. 2002;27(5):524-8.

37. Kapur S, Seeman P. NMDA receptor antagonists ketamine and PCP have direct effects on the dopamine $\mathrm{D}(2)$ and serotonin 5-HT(2)receptors-implications for models of schizophrenia. Mol Psychiatry. 2002;7(8):837-44.

38. Mathew SJ, et al. Ketamine for treatment-resistant unipolar depression: current evidence. CNS Drugs. 2012;26(3):189-204.

39. Berman RM, et al. Antidepressant effects of ketamine in depressed patients. Biol Psychiatry. 2000;47(4):351-4.

40. Maeng S, et al. Cellular mechanisms underlying the antidepressant effects of ketamine: role of alpha-amino-3-hydroxy-5methylisoxazole-4-propionic acid receptors. Biol Psychiatry. 2008;63(4):349-52.

41. Murrough JW, et al. Antidepressant efficacy of ketamine in treatment-resistant major depression: a two-site randomized controlled trial. Am J Psychiatry. 2013;170(10):1134-42.

42. Zarate $\mathrm{CA} \mathrm{Jr}$, et al. A randomized trial of an $N$-methyl-Daspartate antagonist in treatment-resistant major depression. Arch Gen Psychiatry. 2006;63(8):856-64.

43. Mathews DC, Zarate CA Jr. Current status of ketamine and related compounds for depression. J Clin Psychiatry. 2013; 74(5):516-7.

44. Tizabi Y, et al. Antidepressant-like effects of low ketamine dose is associated with increased hippocampal AMPA/NMDA receptor density ratio in female Wistar-Kyoto rats. Neuroscience. 2012;213:72-80.

45. Li N, et al. mTOR-dependent synapse formation underlies the rapid antidepressant effects of NMDA antagonists. Science. 2010;329(5994):959-64.

46. Haile $\mathrm{CN}$, et al. Plasma brain derived neurotrophic factor (BDNF) and response to ketamine in treatment-resistant depression. Int J Neuropsychopharmacol. 2014;17(2):331-6. doi:10.1017/S1461145713001119.

47. Mathisen LC, et al. Effect of ketamine, an NMDA receptor inhibitor, in acute and chronic orofacial pain. Pain. 1995;61(2): 215-20.

48. Oye I, Paulsen O, Maurset A. Effects of ketamine on sensory perception: evidence for a role of $N$-methyl-D-aspartate receptors. J Pharmacol Exp Ther. 1992;260(3):1209-13.

49. White PF, et al. Pharmacology of ketamine isomers in surgical patients. Anesthesiology. 1980;52(3):231-9.

50. Vranken $\mathrm{JH}$, et al. Iontophoretic administration of $\mathrm{S}(+)$-ketamine in patients with intractable central pain: a placebo-controlled trial. Pain. 2005;118(1-2):224-31.

51. Chong C, et al. Development of a sublingual/oral formulation of ketamine for use in neuropathic pain: preliminary findings from a three-way randomized, crossover study. Clin Drug Investig. 2009;29(5):317-24.

52. Niesters M, Martini C, Dahan A. Ketamine for chronic pain: risks and benefits. Br J Clin Pharmacol. 2014;77(2):357-67. doi:10.1111/bcp.12094.

53. Haas DA, Harper DG. Ketamine: a review of its pharmacologic properties and use in ambulatory anesthesia. Anesth Prog. 1992;39(3):61-8.

54. Sigtermans MJ, et al. Ketamine produces effective and longterm pain relief in patients with complex regional pain syndrome type 1. Pain. 2009;145(3):304-11.

55. Soto E, et al. Oral ketamine in the palliative care setting: a review of the literature and case report of a patient with neurofibromatosis type 1 and glomus tumor-associated complex regional pain syndrome. Am J Hosp Palliat Care. 2012;29(4): 308-17. 
56. Bell RF. Ketamine for chronic non-cancer pain. Pain. 2009;141(3):210-4.

57. Bell RF, Eccleston C, Kalso EA. Ketamine as an adjuvant to opioids for cancer pain. Cochrane Database Syst Rev. 2012;11:CD003351.

58. Fisher K, Hagen NA. Analgesic effect of oral ketamine in chronic neuropathic pain of spinal origin: a case report. J Pain Symptom Manag. 1999;18(1):61-6.

59. Eide PK, Stubhaug A, Stenehjem AE. Central dysesthesia pain after traumatic spinal cord injury is dependent on $N$-methyl-D-aspartate receptor activation. Neurosurgery. 1995; 37(6):1080-7.

60. Kvarnstrom A, et al. The analgesic effect of intravenous ketamine and lidocaine on pain after spinal cord injury. Acta Anaesthesiol Scand. 2004;48(4):498-506.

61. Amr YM. Multi-day low dose ketamine infusion as adjuvant to oral gabapentin in spinal cord injury related chronic pain: a prospective, randomized, double blind trial. Pain Physician. 2010;13(3):245-9.

62. Eide PK, et al. Relief of post-herpetic neuralgia with the $N$ methyl-D-aspartic acid receptor antagonist ketamine: a doubleblind, cross-over comparison with morphine and placebo. Pain. 1994;58(3):347-54.

63. Kim K, et al. Ketamine for acute neuropathic pain in patients with spinal cord injury. J Clin Neurosci. 2013;20(6):804-7.

64. Yamamoto T, et al. Pharmacological classification of central post-stroke pain: comparison with the results of chronic motor cortex stimulation therapy. Pain. 1997;72(1-2):5-12.

65. Backonja M, et al. Response of chronic neuropathic pain syndromes to ketamine: a preliminary study. Pain. 1994;56(1):51-7.

66. Max MB, et al. Intravenous infusion of the NMDA antagonist, ketamine, in chronic posttraumatic pain with allodynia: a double-blind comparison to alfentanil and placebo. Clin Neuropharmacol. 1995;18(4):360-8.

67. Felsby $\mathrm{S}$, et al. NMDA receptor blockade in chronic neuropathic pain: a comparison of ketamine and magnesium chloride. Pain. 1996;64(2):283-91.

68. Leung A, et al. Concentration-effect relationship of intravenous alfentanil and ketamine on peripheral neurosensory thresholds, allodynia and hyperalgesia of neuropathic pain. Pain. 2001; 91(1-2):177-87.

69. Jorum E, Warncke T, Stubhaug A. Cold allodynia and hyperalgesia in neuropathic pain: the effect of $N$-methyl-D-aspartate (NMDA) receptor antagonist ketamine-a double-blind, crossover comparison with alfentanil and placebo. Pain. 2003;101(3): 229-35.

70. Kvarnstrom A, et al. The effectiveness of intravenous ketamine and lidocaine on peripheral neuropathic pain. Acta Anaesthesiol Scand. 2003;47(7):868-77.

71. Lynch ME, et al. Topical amitriptyline and ketamine in neuropathic pain syndromes: an open-label study. J Pain. 2005;6(10): 644-9.

72. Huge V, et al. Effects of low-dose intranasal (S)-ketamine in patients with neuropathic pain. Eur J Pain. 2010;14(4): 387-94.

73. Niesters $M$, et al. Influence of ketamine and morphine on descending pain modulation in chronic pain patients: a randomized placebo-controlled cross-over proof-of-concept study. Br J Anaesth. 2013;110(6):1010-6.

74. Gottrup H, et al. Differential effect of ketamine and lidocaine on spontaneous and mechanical evoked pain in patients with nerve injury pain. Anesthesiology. 2006;104(3):527-36.

75. Mahoney JM, et al. Topical ketamine cream in the treatment of painful diabetic neuropathy: a randomized, placebo-controlled, double-blind initial study. J Am Podiatr Med Assoc. 2012; 102(3):178-83.
76. Lynch ME, et al. Topical $2 \%$ amitriptyline and $1 \%$ ketamine in neuropathic pain syndromes: a randomized, double-blind, placebo-controlled trial. Anesthesiology. 2005;103(1):140-6.

77. Barros GA, et al. Topical (S)-ketamine for pain management of postherpetic neuralgia. An Bras Dermatol. 2012;87(3):504-5.

78. Eide PK, Stubhaug A. Relief of glossopharyngeal neuralgia by ketamine-induced $N$-methyl-aspartate receptor blockade. Neurosurgery. 1997;41(2):505-8.

79. Rabben T, Oye I. Interindividual differences in the analgesic response to ketamine in chronic orofacial pain. Eur $\mathrm{J}$ Pain. 2001;5(3):233-40.

80. Baad-Hansen L, et al. Differential effect of intravenous S-ketamine and fentanyl on atypical odontalgia and capsaicin-evoked pain. Pain. 2007;129(1-2):46-54.

81. Persson $\mathrm{J}$, et al. The analgesic effect of racemic ketamine in patients with chronic ischemic pain due to lower extremity arteriosclerosis obliterans. Acta Anaesthesiol Scand. 1998;42(7):750-8.

82. Mitchell AC, Fallon MT. A single infusion of intravenous ketamine improves pain relief in patients with critical limb ischaemia: results of a double blind randomised controlled trial. Pain. 2002;97(3):275-81.

83. Nikolajsen L, et al. The effect of ketamine on phantom pain: a central neuropathic disorder maintained by peripheral input. Pain. 1996;67(1):69-77.

84. Eichenberger U, et al. Chronic phantom limb pain: the effects of calcitonin, ketamine, and their combination on pain and sensory thresholds. Anesth Analg. 2008;106(4):1265-73.

85. Noppers I, et al. Absence of long-term analgesic effect from a short-term S-ketamine infusion on fibromyalgia pain: a randomized, prospective, double blind, active placebo-controlled trial. Eur J Pain. 2011;15(9):942-9.

86. Wurtman RJ. Fibromyalgia and the complex regional pain syndrome: similarities in pathophysiology and treatment. Metabolism. 2010;59(Suppl 1):S37-40.

87. Sorensen J, et al. Fibromyalgia-are there different mechanisms in the processing of pain? A double blind crossover comparison of analgesic drugs. J Rheumatol. 1997;24(8):1615-21.

88. Graven-Nielsen T, et al. Ketamine reduces muscle pain, temporal summation, and referred pain in fibromyalgia patients. Pain. 2000;85(3):483-91.

89. Pickering AE, McCabe CS. Prolonged ketamine infusion as a therapy for complex regional pain syndrome: synergism with antagonism? Br J Clin Pharmacol. 2014;77(2):233-8. doi:10. 1111/bcp.12157.

90. Price DD, et al. NMDA-receptor antagonists and opioid receptor interactions as related to analgesia and tolerance. $J$ Pain Symptom Manag. 2000;19(1 Suppl):S7-11.

91. Schwartzman RJ, et al. Outpatient intravenous ketamine for the treatment of complex regional pain syndrome: a double-blind placebo controlled study. Pain. 2009;147(1-3):107-15.

92. Schilder JC, et al. Pain relief is associated with improvement in motor function in complex regional pain syndrome type 1: secondary analysis of a placebo-controlled study on the effects of ketamine. J Pain. 2013;14(11):1514-21. doi:10.1016/j.jpain. 2013.07.013.

93. Dahan A, et al. Population pharmacokinetic-pharmacodynamic modeling of ketamine-induced pain relief of chronic pain. Eur $\mathrm{J}$ Pain. 2011;15(3):258-67.

94. Correll GE, et al. Subanesthetic ketamine infusion therapy: a retrospective analysis of a novel therapeutic approach to complex regional pain syndrome. Pain Med. 2004;5(3):263-75.

95. Finch PM, Knudsen L, Drummond PD. Reduction of allodynia in patients with complex regional pain syndrome: a double-blind placebo-controlled trial of topical ketamine. Pain. 2009; 146(1-2):18-25. 
96. Du Mont J, et al. Drug-facilitated sexual assault in Ontario, Canada: toxicological and DNA findings. J Forensic Leg Med. 2010;17(6):333-8.

97. Albright JA, Stevens SA, Beussman DJ. Detecting ketamine in beverage residues: application in date rape detection. Drug Test Anal. 2012;4(5):337-41.

98. Kiefer RT, et al. Efficacy of ketamine in anesthetic dosage for the treatment of refractory complex regional pain syndrome: an open-label phase II study. Pain Med. 2008;9(8):1173-201.

99. Kirkpatrick AF, Lubenow T. Regarding Bell and Moore, Intravenous ketamine for CRPS: making too much of too little? Pain 2010;150:10-11. Pain. 2010;151(2):556.

100. Schwartzman RJ, Alexander GM, Grothusen JR. The use of ketamine in complex regional pain syndrome: possible mechanisms. Expert Rev Neurother. 2011;11(5):719-34.

101. Olney JW, Labruyere J, Price MT. Pathological changes induced in cerebrocortical neurons by phencyclidine and related drugs. Science. 1989;244(4910):1360-2.

102. Olney JW. Excitotoxic amino acids and neuropsychiatric disorders. Annu Rev Pharmacol Toxicol. 1990;30:47-71.

103. Noppers IM, et al. Drug-induced liver injury following a repeated course of ketamine treatment for chronic pain in CRPS type 1 patients: a report of 3 cases. Pain. 2011;152(9):2173-8.

104. Shahani R, et al. Ketamine-associated ulcerative cystitis: a new clinical entity. Urology. 2007;69(5):810-2.

105. Chu PS, et al. The destruction of the lower urinary tract by ketamine abuse: a new syndrome? BJU Int. 2008;102(11): $1616-22$.
106. Winstock AR, et al. The prevalence and natural history of urinary symptoms among recreational ketamine users. BJU Int. 2012;110(11):1762-6.

107. Mak SK, et al. Lower urinary tract changes in young adults using ketamine. J Urol. 2011;186(2):610-4.

108. Chen $\mathrm{CH}$, et al. Ketamine-snorting associated cystitis. J Formos Med Assoc. 2011;110(12):787-91.

109. Niesters M, Dahan A. Pharmacokinetic and pharmacodynamic considerations for NMDA receptor antagonists in the treatment of chronic neuropathic pain. Expert Opin Drug Metab Toxicol. 2012;8(11):1409-17.

110. Miller LR, Cano A. Comorbid chronic pain and depression: who is at risk? J Pain. 2009;10(6):619-27.

111. Walker AK, et al. Neuroinflammation and comorbidity of pain and depression. Pharmacol Rev. 2014;66(1):80-101.

112. Haines DR, Gaines SP. $N$ of 1 randomised controlled trials of oral ketamine in patients with chronic pain. Pain. 1999;83(2):283-7.

113. Furuhashi-Yonaha A, et al. Short- and long-term efficacy of oral ketamine in eight chronic-pain patients. Can J Anaesth. 2002;49(8):886-7.

114. Rabben T, Skjelbred P, Oye I. Prolonged analgesic effect of ketamine, an $N$-methyl-D-aspartate receptor inhibitor, in patients with chronic pain. J Pharmacol Exp Ther. 1999;289(2):1060-6.

115. Hardy J, et al. Randomized, double-blind, placebo-controlled study to assess the efficacy and toxicity of subcutaneous ketamine in the management of cancer pain. J Clin Oncol. 2012;30(29):3611-7. 